\title{
BMJ Global Health IndOSS-Assam: investigating the feasibility of introducing a simple maternal morbidity surveillance and research system in Assam, India
}

\author{
Manisha Nair, ${ }^{1}$ Manoj K Choudhury, ${ }^{2}$ Saswati S Choudhury, ${ }^{3}$ Swapna D Kakoty, ${ }^{3}$ \\ Umesh C Sarma, ${ }^{2}$ Premila Webster, ${ }^{4}$ Marian Knight, ${ }^{1}$ On behalf of the IndOSS- \\ Assam steering committee
}

To cite: Nair $\mathrm{M}$ Choudhury MK, Choudhury SS, et al. IndOSSAssam: investigating the feasibility of introducing a simple maternal morbidity surveillance and research system in Assam, India. BMJ Global Health 2016;1: e000024. doi:10.1136/ bmjgh-2015-000024

MKC and SSC contributed equally.

Received 15 December 2015 Revised 16 February 2016 Accepted 11 March 2016

\section{CrossMark}

${ }^{1}$ National Perinatal Epidemiology Unit (NPEU), Nuffield Department of Population Health, University of Oxford, Oxford, UK

${ }^{2}$ Srimanta Sankaradeva University of Health Sciences, Guwahati, Assam, India ${ }^{3}$ FAA Medical College, Barpeta, Assam, India ${ }^{4}$ Oxford School of Public Health, Oxford Deanery, Oxford, UK

Correspondence to Dr Manisha Nair; manisha.nair@npeu.ox.ac.uk

\section{ABSTRACT}

Objective: To assess the feasibility of establishing a simple maternal morbidity surveillance system in Assam (Indian Obstetric Surveillance System-Assam (IndOSS-Assam)) to investigate the incidence and trends in severe maternal complications. This study presents the surveillance platform of IndOSS-Assam. Design: Four tasks were undertaken: (1) setting up of a steering committee; (2) establishing priorities for the region; (3) mapping of surveillance sites; (4) piloting case-notification systems in selected centres.

Setting: Two government tertiary hospitals in the state.

Study population: Pregnant women delivering in the hospitals between March and August 2015.

Main outcome measures: Incidence and case fatality rates with $95 \%$ Cls.

Results: Local stakeholder ownership and a simple uncomplicated anonymous system for case notification were the key strengths of this project. Cases and deaths were reported for six conditions: eclampsia, postpartum haemorrhage, puerperal sepsis, septic abortion, uterine rupture and anaemic heart failure. Among 10475 women delivering over 6 months, 402 had one of these conditions and 66 died (case fatality $16 \%)$. The incidence of eclampsia was 17 per 1000 deliveries ( $95 \% \mathrm{Cl} 14$ to 19$)$, postpartum haemorrhage was 11 per 1000 deliveries ( $95 \% \mathrm{Cl} 10$ to 13) and anaemic heart failure was 3 per 1000 deliveries $(95 \%$ $\mathrm{Cl} 2$ to 5). For each of the other three conditionspuerperal sepsis, septic abortion and uterine rupturethe incidence rate was 2 per 1000 deliveries.

Conclusions: IndOSS-Assam was shown to be a feasible and simple system for ongoing surveillance of maternal morbidity that can be used to monitor the trends in the incidence of specific severe lifethreatening conditions during pregnancy.

\section{INTRODUCTION}

India has the highest number of maternal deaths worldwide (50 000 maternal deaths in 2013), ${ }^{1}$ and within India, the north-eastern

\section{Key questions}

What is already known about this subject?

- In low and middle income countries, there is a continued focus on increasing the proportion of facilitybased deliveries, thereby increasing the need to monitor the quality of maternity care in hospitals.

- Case reviews of severe life-threatening maternal conditions have been initiated in a few countries such as South Africa, Benin, Ghana, Ivory Coast, Malaysia and Papua New Guinea, but these studies do not describe use - in low and middle income countries-of a hospital-based surveillance system to measure incidence and case-fatality of severe maternal morbidity, on an ongoing basis.

What are the new findings?

- This study showed the feasibility of establishing a simple anonymous hospital-based obstetric surveillance system (the Indian Obstetric Surveillance System-Assam (IndOSS-Assam)) as a first step towards estimating the incidence and case-fatality of severe life-threatening complications during pregnancy and childbirth in the Indian state of Assam.

- The surveillance platform of IndOSS-Assam is already established in the two medical colleges that participated in this pilot study. Involvement of local clinicians, policymakers, researchers, public health specialists and academics, from the inception of the project to testing the system, showed that there is willingness and commitment to establish and scale up IndOSS-Assam to other hospitals in the state.

\section{Recommendations for policy}

- This pilot study showed a high incidence of eclampsia, postpartum haemorrhage, puerperal sepsis, septic abortion, uterine rupture and heart failure due to severe anaemia in pregnancy in the state, along with a high-case fatality rate. This suggests the need to focus research and policies to improve management of these conditions to reduce the burden of maternal mortality and morbidity in the state. 
state of Assam has a high maternal mortality ratio $\left(M M R=301 / 100000\right.$ live births in 2012-2013), ${ }^{2}$ higher than the national average (MMR=178/100 000 live births in 2010-2012. ${ }^{3}$ It has been hypothesised from the existing demographic and health surveys that anaemia and teenage pregnancy are important contributors to this high burden of maternal deaths in Assam, but there are limited data to investigate this. ${ }^{4}{ }^{5}$ There are no up-to-date epidemiological data to refine existing programmes and policies, nor those to develop new ones. Routine surveillance systems would provide the much needed data to investigate the risk factors for maternal morbidity and mortality in the state, as well as to assess the impact of ongoing maternal health programmes such as the 'Mamoni Scheme' and Janai Suraksha Yojana. These cash incentive schemes encourage pregnant women to undergo at least three antenatal checkups and to deliver in a health institution. ${ }^{67}$ Currently, the electronic maternal death reporting system (e-MDR) of the national Health Mission in the state collates information on the number of maternal deaths per district per month. ${ }^{8}$ However, deaths are only the tip of the iceberg and a large number of women develop severe morbidity due to these conditions.

Establishing a state-wide hospital-based obstetric surveillance and research system is a first step towards generating evidence about the major risk and prognostic factors for maternal morbidity and mortality in the state of Assam. Audits are not generally acceptable due to concerns about attribution of blame, ${ }^{9}$ and thus an anonymous data collection system provides an ideal route to obtaining the appropriate information to conduct much needed research and surveillance. The proportion of childbirths in a health institution in Assam has been reported to have increased from $58 \%$ in $2010-2011^{10}$ to $66 \%$ in 2012-2013 (rural 63\% and urban $84 \%),{ }^{11}$ thereby raising the need for a meaningful and straightforward means of monitoring the quality of maternity care in the hospitals. Once established, a surveillance system could provide a platform to conduct epidemiological studies, to generate evidence to prevent severe maternal morbidity (defined as life-threatening complications during pregnancy and childbirth) and to guide management of severe obstetric complications to reduce mortality.

However, existing approaches, such as the WHO nearmiss approach, which has 25 markers for severe maternal morbidity, ${ }^{12}$ are complex and difficult to implement in practice, and not all criteria are reported to be relevant to the Indian context. ${ }^{13}{ }^{14}$ The UK has successfully implemented a surveillance and research system, the UK Obstetric Surveillance System (UKOSS), ${ }^{15}$ which has enabled the collection of anonymous information on a range of uncommon but severe pregnancy complications nationally. Since its inception in 2005, UKOSS has successfully generated evidence to guide prevention and management of major obstetric complications, and to inform policies, service planning and address patient safety issues. ${ }^{16}$ This has encouraged Australia, New Zealand and several countries in Europe to establish similar systems. ${ }^{17}$ The aim of this project was to assess the feasibility of establishing a simple obstetric surveillance and research system in Assam (the Indian Obstetric Surveillance System-Assam (IndOSS-Assam)) using the UKOSS model in order to describe the changing epidemiology of risk factors, management and outcomes associated with maternal deaths and specific morbidities in the state. IndOSS-Assam has two components: surveillance and research. This paper presents the results of the pilot study that assessed the feasibility of setting up the surveillance platform of IndOSS-Assam.

\section{METHODS}

The objective of this pilot study was to adapt the UKOSS methodology to the context of Assam in order to develop a simple maternal morbidity surveillance system for the state (IndOSS-Assam). Details of the UKOSS methodology are described elsewhere. ${ }^{15}{ }^{16}$ Briefly, UKOSS is a surveillance and research platform that enables collection of information on specific pregnancy complications through case notification cards sent to nominated reporting doctors and midwives in all consultant-led obstetric units in the UK every month, with an approach of 'nil-reporting'. ${ }^{15}$ For every case reported, details are collected on a data collection form by the clinician responsible for managing the case. Rigorous follow-up of non-responders ensures completeness of data. ${ }^{15}$ A similar methodology was used for IndOSS-Assam.

Four main tasks were undertaken in the development and piloting of the surveillance platform of the IndOSS-Assam: (1) setting up of a steering committee; (2) establishing priorities for the region; (3) mapping of reporting hospitals; and (4) piloting the system of case notification cards in selected centres. A fifth task was to assess the feasibility of using routine medical records for conducting epidemiological studies through the IndOSS-Assam 'research platform' in order to describe the risk factors, management and outcomes associated with specific life-threatening complications during pregnancy and child birth in the state of Assam. The details are presented in a separate paper. ${ }^{18}$ The activities undertaken to examine the feasibility of establishing IndOSS-Assam are summarised in figure 1.

The conditions to be included in surveillance during the pilot study were identified by stakeholder consultation with members of the steering committee and others, based on their main concerns about severe maternal mortalities specific to Assam and informed by an initial analysis of the causes of death reported through the e-MDR. ${ }^{18}$

Two tertiary hospitals, Fakhruddin Ali Ahmed Medical College and Hospital (FAAMCH), Barpeta and Guwahati Medical College and Hospital (GMCH), Guwahati, were purposively selected by the steering 


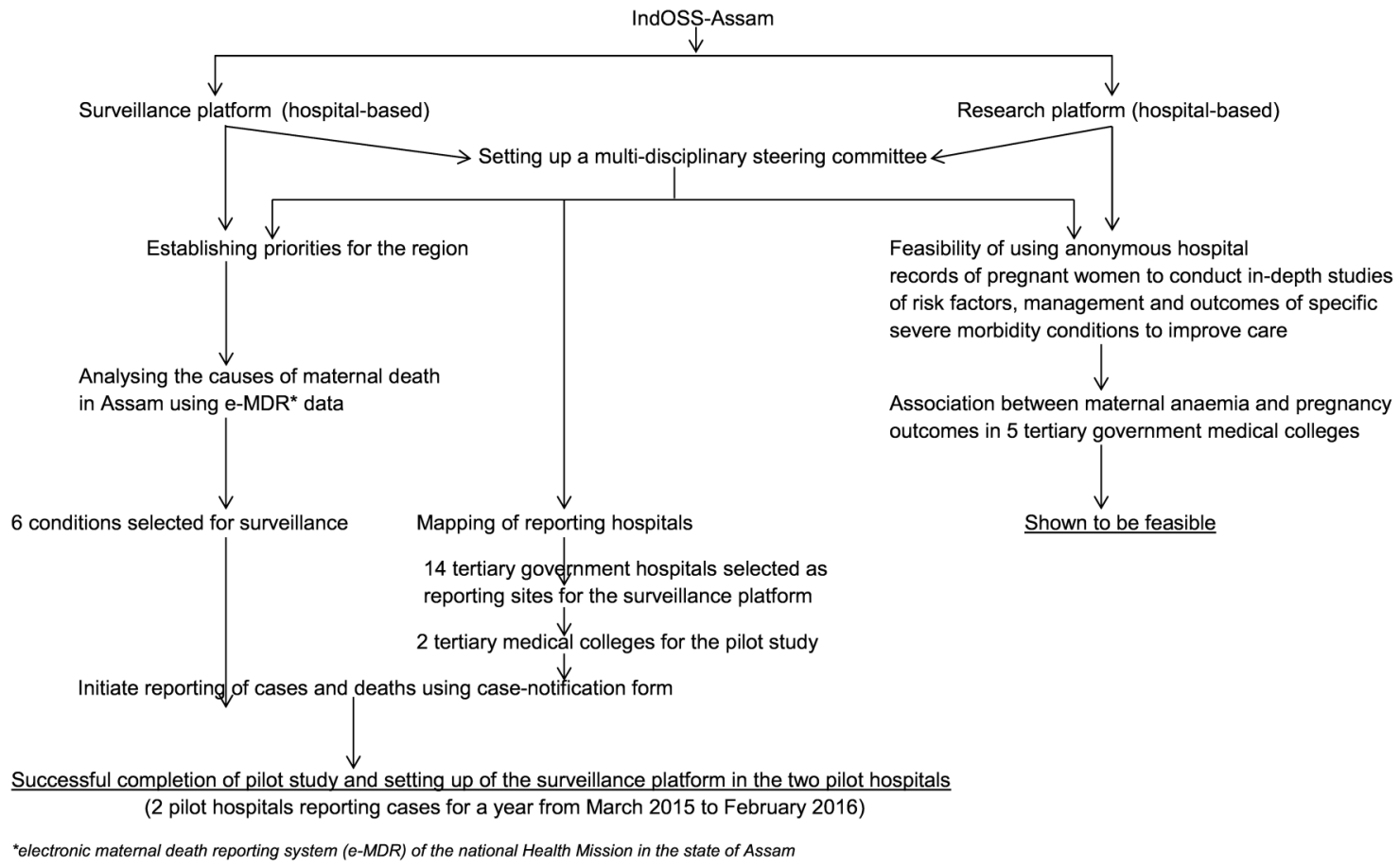

Figure 1 Flow chart showing activities undertaken to examine the feasibility of establishing IndOSS-Assam.

committee as centres for pilot testing the case notification system of IndOSS-Assam, to include one hospital in the state capital and one more peripheral hospital. A case notification card (figure 2) was designed to collect information on the number of cases and deaths due to the six selected priority conditions associated with increased risk of maternal mortality in the state. The IndOSS-Assam monthly case notification system was launched in March 2015 in the two medical colleges under the supervision of the steering committee.

\section{Statistical analyses}

We compiled the information from the case notification cards and calculated the proportion of cases as a percentage of the total deliveries with $95 \%$ CIs and the case fatality rate with $95 \%$ CI for each condition in each hospital.

\section{RESULTS}

\section{Setting up a steering committee}

A multidisciplinary steering committee was successfully constituted in the state, including senior representatives from obstetrics, medical education, public health, medical research and university organisations, as well as individual representatives from professional specialties. A total of six steering committee meetings were held during a period of 18 months, either in person or by teleconference, including in consultation with UKOSS researchers, in order to adapt the UKOSS methodology to the context of Assam.

\section{Establishing priorities for the region}

There were 3753 maternal deaths reported through the e-MDR between April 2011 and August 2014, which is approximately half of the estimated 6333 deaths based on the MMR of 301/100000 live births. The main causes of death were reported to be anaemia, eclampsia, sepsis, haemorrhage, obstructed labour and septic abortion (figure 3). For almost half the cases, the cause was not known, or reported as 'others'. Almost $64 \%$ of the deaths occurred in hospitals (figure 4), which further confirmed that a hospital-based surveillance system would be able to capture a majority of the cases of severe maternal morbidity and mortality.

Based on the analyses of the causes of death and stakeholder consultation, six conditions were included in the pilot phase (phase-1) of IndOSS-Assam: five causes of direct maternal mortality-eclampsia, postpartum haemorrhage (PPH), puerperal sepsis, septic abortion and uterine rupture, and one suspected cause of indirect maternal death in the state-anaemic heart failure (heart failure during pregnancy and delivery as a consequence of severe anaemia ${ }^{19}$ ).

\section{Mapping of reporting hospitals}

The major tertiary and community government and private hospitals were identified and manually mapped to assess their geographical distribution. All 14 major tertiary government hospitals were identified (figure 5).

\section{Piloting the surveillance system in two selected centres}

The pilot system was successfully established, with $100 \%$ of monthly reports returned to the steering committee 
Figure 2 IndOSS-Assam case notification card.

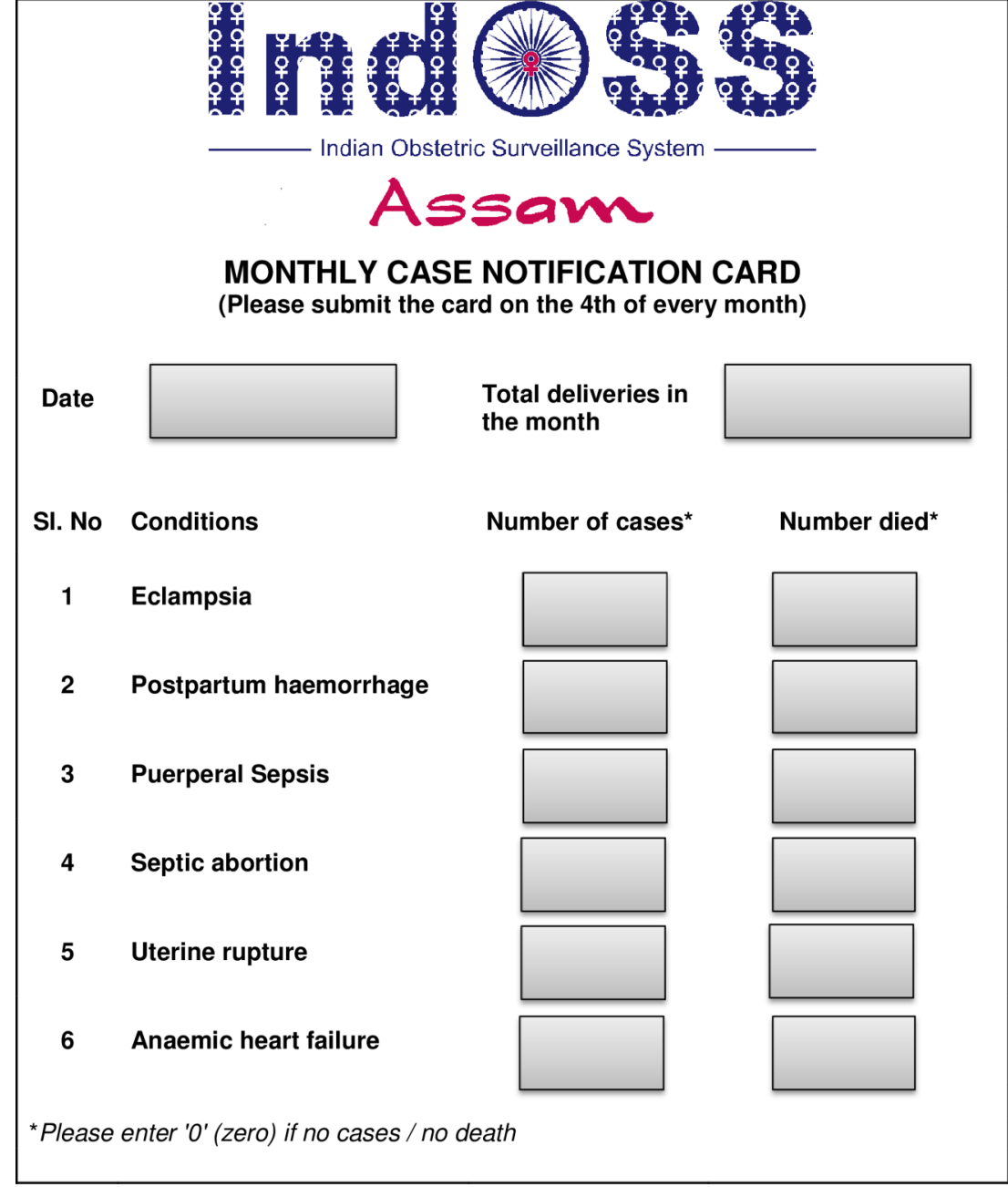

at the Srimanta Sankaradeva University of Health Sciences for the two medical colleges during the pilot phase between March and August 2015. Paper-based case notification cards were received in a timely manner, nil-reporting ensured completeness and there were no identified problems in reporting. The reporting was overseen by either a senior obstetrician or the Head of the Department of Obstetrics and Gynaecology in each medical college.

There were a total of 10475 deliveries in the two medical colleges participating in IndOSS-Assam in the 6 months of the pilot study; 402 cases and 66 deaths as a result of one of the six conditions under surveillance were reported (table 1 ). The incidence of eclampsia was 17 per 1000 deliveries (95\% CI 14 to 19), PPH was 11 per 1000 deliveries (95\% CI 10 to 13 ) and anaemic heart failure was 3 per 1000 deliveries (95\% CI 2 to 5). For each of the other three conditions-puerperal sepsis, septic abortion and uterine rupture-the incidence rate was 2 per 1000 deliveries. Case fatality due to these conditions was high, $16 \%$ (95\% CI $13 \%$ to $20 \%$ ) of women who were diagnosed with these conditions died, the highest case fatality rate being for puerperal sepsis and anaemic heart failure (table 1 ).

\section{DISCUSSION}

This study showed that setting up a simple surveillance system is feasible, and that there is also willingness and enthusiasm among the clinicians in the state to establish IndOSS-Assam. Data collected during the pilot study on six conditions, eclampsia, PPH, puerperal sepsis, septic abortion, uterine rupture and anaemic heart failure, showed a high incidence (4\% of all deliveries) and fatality $(16 \%$ of all cases) associated with these conditions among pregnant women who delivered in the two pilot hospitals.

A number of factors were felt to have contributed to the success of the pilot project, the most important being local stakeholders including clinicians, public health specialists and academics from the medical colleges, hospitals and the university, taking ownership and driving the project, with support from UKOSS researchers. The other key factor was the simple straightforward design of the IndOSS-Assam system. Regular meetings with the steering committee, to identify hurdles in implementing the system and anonymous reporting of cases and deaths, without attribution of blame, were other strengths identified by the steering committee members and the reporting clinicians. 
Figure 3 Causes of maternal deaths in Assam-April 2012 to August 2014.*

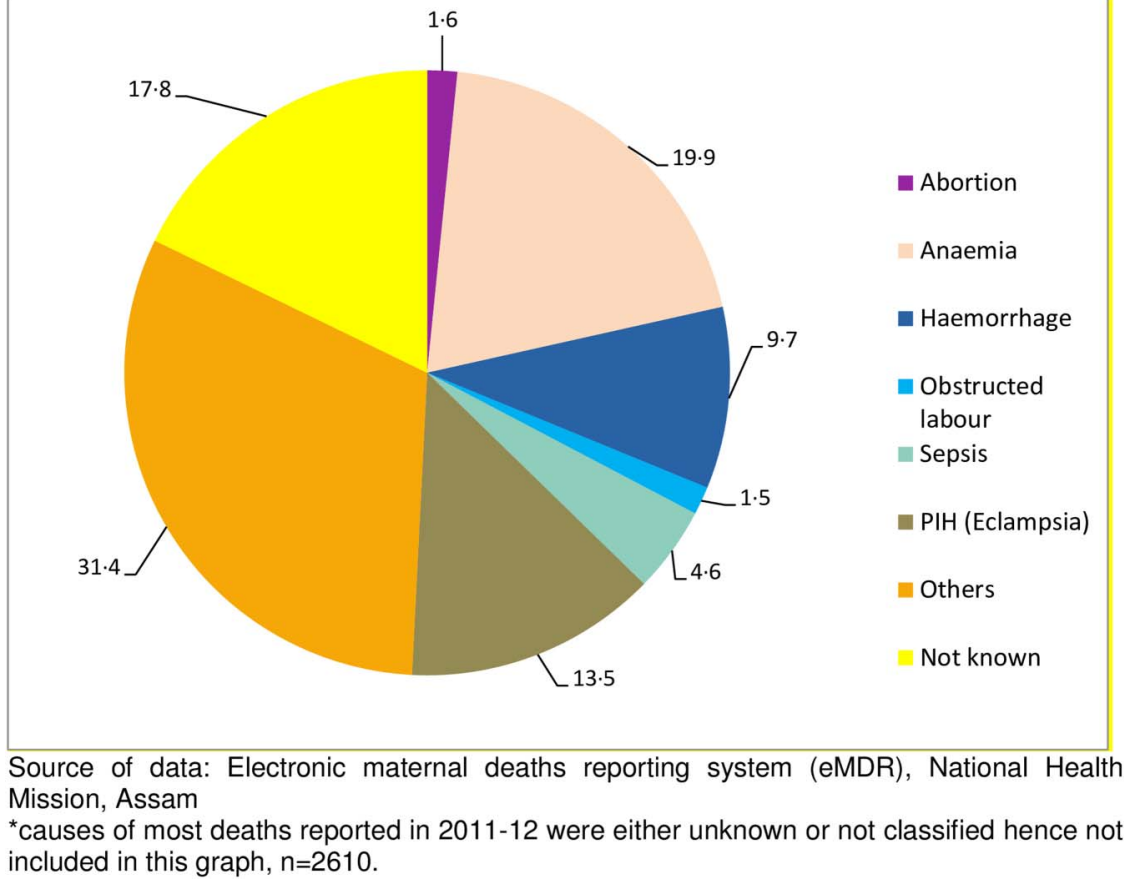

included in this graph, $n=2610$.

\section{Strengths and limitations of this study}

Despite the fact that Assam has a high MMR in India, little work has been undertaken, to date, to generate good quality evidence about the incidence of severe lifethreatening complications during pregnancy and childbirth, with the aim of monitoring the patterns and trends of these conditions in the state. The surveillance platform of the IndOSS-Assam can be used to generate evidence about trends in the incidence and case-fatality of important life-threatening conditions on an ongoing basis. This will help direct research and policies to improve the management of conditions with high incidence and casefatality, in order to reduce the burden of maternal mortality and morbidity in the state. This study demonstrated the feasibility of establishing IndOSS-Assam as a hospital-based surveillance system in the state. IndOSS-Assam, being an anonymised data collection system, avoids the attribution

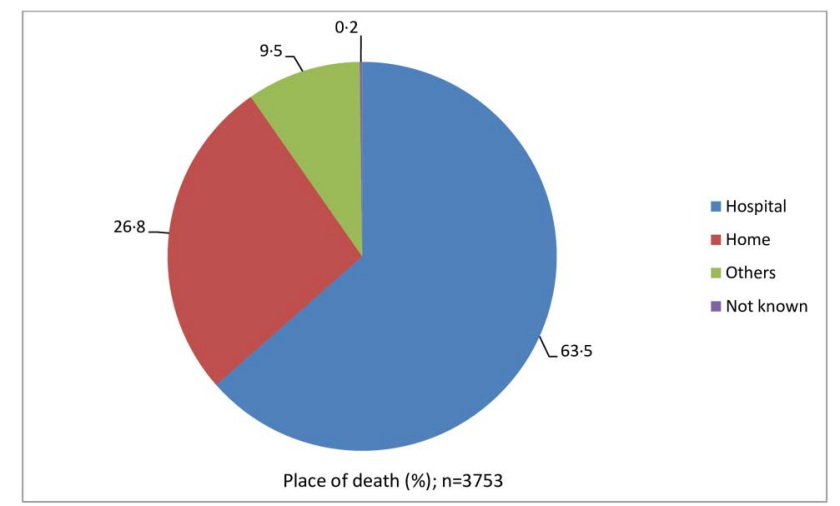

Source of data: Electronic maternal deaths reporting system (eMDR), National Health Mission, Assam

Figure 4 Maternal deaths in Assam from April 2011 to August 2014: PLACE OF DEATH. of blame while generating robust incidence estimates to improve maternal health in the state.

Although we were able to estimate hospital-based incidence rates for six major causes of maternal mortality and morbidity in Assam, these do not necessarily reflect the population-level incidence of these conditions. The estimated incidence and fatality could be lower than the true population incidence, as not all pregnant women deliver in a health facility. It is also possible that our estimates are higher than the true population rate, since pregnant women with serious complications are more likely to be referred to the tertiary hospitals. High fatality could be due to late referral of cases, but it could also be associated with inadequate management and care during pregnancy and delivery. Nevertheless, this pilot study showed that 1 in 25 women who delivered in two tertiary hospitals (FAAMCH and GMCH) suffered from one of the six major causes of maternal deaths in the state and 1 in 130 women died as a result of these conditions. This further justifies the need for establishing IndOSS-Assam as a platform for ongoing surveillance and research in the state. Expanding the network of reporting hospitals for IndOSS-Assam to all tertiary government hospitals and major private maternity hospitals in subsequent phases of the project would ensure that information on the large majority of cases with severe complications are captured.

\section{Findings in relation to other studies}

An earlier study in the FAAMCH tertiary hospital identified 66 cases of severe maternal morbidity in 1729 deliveries between June and October 2014, of which 39\% were eclampsia and $24 \% \mathrm{PPH},{ }^{20}$ leading to an estimated incidence rate of $1.5 \%$ for eclampsia and about $1 \%$ for $\mathrm{PPH}$ among the total deliveries. These rates are a half to 

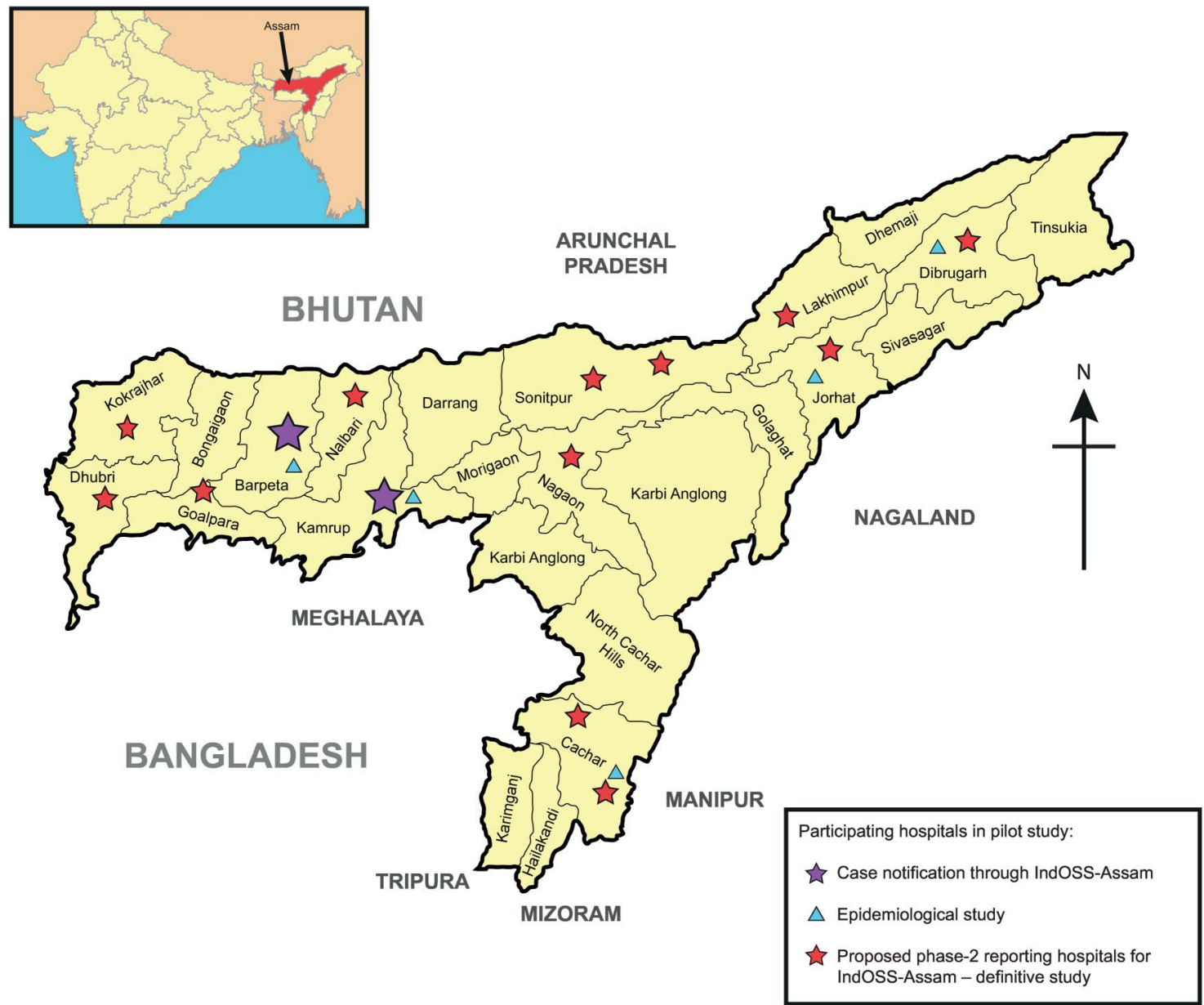

Figure 5 Geographical mapping of future reporting hospitals for IndOSS-Assam and reporting hospitals taking part in the pilot study.

two-thirds lower than that estimated by the IndOSS-Assam active surveillance in the same hospital between March and August 2015. The maternal death reviews in the state show eclampsia, $\mathrm{PPH}$ and anaemia to be the major causes of maternal mortality (figure 3), however, maternal mortality rates are not calculable as denominator information about the number of women delivering is not available. The added value of IndOSS is not in estimating the number of deaths due to these known causes of maternal death in Assam, but to monitor the incidence and case-fatality of these important conditions. Allied studies aim to improve their in-hospital management, as the number of facility-based deliveries increase in the state, in order to reduce maternal morbidity and mortality. IndOSS-Assam showed a high incidence of these conditions among pregnant women who delivered in the two pilot centres as well as high fatality rates associated with anaemic heart failure and sepsis.

The million death study estimated that a quarter of the maternal deaths in India were due to PPH. ${ }^{21}$ 'Dead women talking', a civil society report on maternal deaths in India, identified anaemia to be the second largest cause of maternal death in India after PPH. ${ }^{22}$ Of the 22 women (of 124) who were reported to die from anaemia, 11 had cardiac failure during labour or delivery and in at least 8 of the 29 deaths from $\mathrm{PPH}$, anaemia was a contributing factor. ${ }^{22}$ Another study in India reported a prevalence of $9.4 \%$ cardiac failure among women with severe anaemia. ${ }^{23}$ This is the first system in Assam to initiate data collection to estimate the incidence of maternal morbidity on an ongoing basis, including cardiac failure due to anaemia during pregnancy. Prior to this study, the incidence and case-fatality rates due to anaemic heart failure among pregnant women in Assam were not known. Through the research platform, we were also able to conduct a retrospective cohort study on the adverse maternal and fetal outcomes of anaemia during pregnancy. As mentioned above, the findings are presented separately. ${ }^{18}$

The incidence $(2 \%)$ and case-fatality $(12 \%)$ rates of eclampsia estimated by the IndOSS-Assam pilot study in the two medical colleges are higher than the rates reported by hospital-based studies in other states in India. A prospective study conducted in a hospital in Nagpur between January 2008 and December 2010 estimated the incidence of eclampsia to be $0.9 \%$ and casefatality $5.5 \% .{ }^{24}$ Similar rates were reported by a teaching 
Table 1 Total cases notified in 6 months of pilot study through the IndOSS-Assam

\begin{tabular}{|c|c|c|c|c|c|}
\hline Conditions under surveillance & Cases & Deaths & $\begin{array}{l}\text { Percentage of cases } \\
(95 \% \mathrm{Cl})\end{array}$ & $\begin{array}{l}\text { Percentage of fatality } \\
(95 \% \mathrm{Cl})\end{array}$ & Total deliveries \\
\hline \multicolumn{6}{|l|}{ FAAMCH, Barpeta } \\
\hline $\mathrm{PPH}$ & 44 & 5 & $1.4(1.0$ to 1.9$)$ & 11.4 (3.8 to 24.6$)$ & \\
\hline Puerperal sepsis & 6 & 1 & $0.2(0.1$ to 0.4$)$ & $16.7(0.4$ to 64.1$)$ & \\
\hline Anaemic heart failure & 17 & 5 & $0.5(0.3$ to 0.9$)$ & $29.4(10.3$ to 55.9$)$ & \\
\hline Total & 178 & 18 & 5.7 (4.9 to 6.5$)$ & $10 \cdot 1(6 \cdot 1$ to $15 \cdot 5)$ & \\
\hline \multicolumn{6}{|l|}{ GMCH, Guwahati } \\
\hline Eclampsia & 82 & 16 & $1.1(0.9$ to 1.4$)$ & $19.5(11.6$ to $29 \cdot 7)$ & 7330 \\
\hline Uterine rupture & 17 & 2 & $0.2(0.1$ to 0.4$)$ & $11.8(1.5$ to 36.4$)$ & \\
\hline Anaemic heart failure & 18 & 9 & $0.2(0.1$ to 0.4$)$ & $50 \cdot 0$ (26 to 74$)$ & \\
\hline Total & 224 & 48 & 3.1 (3.0 to 3.5$)$ & $21 \cdot 4(16 \cdot 2$ to $27 \cdot 4)$ & \\
\hline Both sites & \multicolumn{5}{|c|}{ Total in two tertiary hospitals in 6 months of pilot study } \\
\hline Eclampsia & 174 & 21 & $1.7(1.4$ to 1.9$)$ & $12 \cdot 1(7.6$ to $17 \cdot 9)$ & 10475 \\
\hline $\mathrm{PPH}$ & 118 & 10 & $1.1(1.0$ to 1.3$)$ & $8.5(4.1$ to $15 \cdot 0)$ & \\
\hline Puerperal sepsis & 23 & 10 & $0.2(0.1$ to 0.3$)$ & $43.5(23.2$ to 65.5$)$ & \\
\hline Septic abortion & 26 & 8 & $0.2(0.2$ to 0.4$)$ & $30.8(14.3$ to $51 \cdot 8)$ & \\
\hline Uterine rupture & 26 & 3 & $0.2(0.2$ to 0.4$)$ & $11.5(2.4$ to 30.2$)$ & \\
\hline
\end{tabular}

FAAMCH, Fakhruddin Ali Ahmed Medical College and Hospital; GMCH, Guwahati Medical College and Hospital; PPH, postpartum haemorrhage.

hospital in Karnataka (incidence $1 \%$ and case-fatality $4 \%) .{ }^{25}$ A study in a tertiary hospital in Kolkata identified PPH to be a major cause of maternal morbidity, with an estimated case-fatality rate of $7.5 \%{ }^{26}$ While puerperal sepsis is a known cause of maternal mortality in India, we found only one study that provided estimated incidence of puerperal sepsis in six hospitals in the state of Gujarat. ${ }^{27}$ The study reported an incidence of $4 \%$, which is higher than the $0.2 \%$ estimated through IndOSS-Assam. ${ }^{27}$ A study that reviewed the records of all deliveries in a tertiary hospital in Chandigarh over a period of 15 years (January 1988 to December 2002) found 315 cases of septic abortion among 46417 deliveries, giving an incidence of $0.7 \%$, which is comparable to that estimated through IndOSS-Assam in the two pilot hospitals, although the case-fatality rate in the Assam hospitals $(31 \%)$ was higher than that estimated in the Chandigarh hospital (25\%). ${ }^{28} \mathrm{~A}$ hospital in central India estimated an incidence of $0.06 \%$ for uterine rupture over a period of 12 years (1989-2000), with a case-fatality rate of $6 \% .{ }^{29}$ It therefore appears that the incidence rates of the six conditions estimated through the IndOSS-Assam are, in general, comparable with the incidence of these conditions estimated by hospitalbased studies in others parts of India, but the reported case-fatality rates in the two hospitals in Assam are much higher, further justifying the need for establishing IndOSS-Assam.

\section{Implications and future research}

IndOSS-Assam has been shown to be a feasible and simple system to initiate surveillance of the major causes of maternal death in the state, to estimate the incidence and case-fatality rates on an ongoing basis. An examination of the research platform alongside the feasibility study for setting up the surveillance system showed that, through IndOSS-Assam, detailed studies on these conditions can be conducted to identify the specific preventive and management factors that need to be improved to reduce the deaths and severe complications associated with the conditions. ${ }^{18}$ For example, the study showed that iron deficiency anaemia during pregnancy is associated with increased odds of $\mathrm{PPH}$, and the risk increased by 17 -fold among women with moderatesevere anaemia who underwent induction of labour and by 19-fold among women who had infection and 
moderate-severe anaemia. ${ }^{18}$ These findings raise important questions about how pregnant women with moderate-severe anaemia should be managed during labour and delivery. At present, there are no clear guidelines, and lessons learnt from further studies can be used to inform local and global guidance about management of labour and delivery among pregnant women with moderate-severe anaemia. The implementation and outcomes of the resultant guidelines/actions can be monitored through the research and surveillance platform of IndOSS-Assam. In addition to generating new hypotheses, the research platform will be used to investigate the gaps in management of women with specific life-threatening conditions on a rolling basis, as well as to identify good practices. The data collected through both platforms, being anonymous, avoid attribution of blame to any particular hospital or healthcare provider.

Involvement of local clinicians, policymakers, researchers, public health specialists and academics from the inception of the project to testing the system shows that there is willingness and commitment to establish and scale up IndOSS-Assam to other public and private maternity hospitals in the state. We will explore the possibility of integrating the surveillance component of IndOSS-Assam with the existing health management information system of the National Health Mission in Assam. Integration would minimise duplication of effort, enable sustainable scaling up of the surveillance platform to all government health centres in the state, streamline data flow and improve government ownership of the data, facilitating timely action. In the longer term, the IndOSS-Assam model could be used in other states in India to encourage the establishment of a national system.

\section{Handling editor Seye Abimbola}

Contributors MN designed the study, trained the field staff, conducted the literature searches, planned and carried out the data analysis, interpreted the data and wrote the first draft of the article. MKC designed the study, trained the field staff, supervised data collection and data entry, and edited the manuscript. SSC designed the study, trained the field staff, supervised data collection and data entry, and edited the manuscript. SDK designed the study, trained the field staff and edited the manuscript. UCS designed the study, trained the field staff, supervised data collection and edited the manuscript. PW designed the study and edited the manuscript. MK designed the study, contributed to the data analysis plan, data interpretation and to writing the article.

Funding This study was funded by the John Fell Oxford University Press (OUP) Research Fund, PRAC/JF/131/124; and by the Srimanta Sankaradeva University of Health Sciences, Assam. Marian Knight is funded by a National Institute for Health Research (NIHR), Research Professorship. The funding sources had no role in the study, and the researchers were independent from the funders. The funders had no role in study design, data collection and analysis, and decision to publish, nor in preparation of the manuscript.

Competing interests None declared.

Ethics approval The IndOSS-Assam feasibility study was approved by the institutional ethics committee of Srimanta Sankaradeva University of Health Sciences (Number SSUHS/Ethics/2014/1, dated 27 June 2014); the Health Ministry's Screening Committee, Indian Council of Medical Research (Number
5/7/12 12/14-RCH, dated 25 September 2014) and the University of Oxford's Oxford Tropical Research Ethics Committee (OxTRTEC Reference 57-14).

Provenance and peer review Not commissioned; externally peer reviewed.

Data sharing statement No additional data are available.

Open Access This is an Open Access article distributed in accordance with the Creative Commons Attribution Non Commercial (CC BY-NC 4.0) license, which permits others to distribute, remix, adapt, build upon this work noncommercially, and license their derivative works on different terms, provided the original work is properly cited and the use is non-commercial. See: http:// creativecommons.org/licenses/by-nc/4.0/

\section{REFERENCES}

1. WHO, UNICEF, UNFPA, et al. Trends in maternal mortality: 1990 to 2013. Estimates by WHO, UNICEF, UNFPA, The World Bank and the United Nations Population Division. Geneva: World Health Organisation, 2014.

2. Office of Registrar General India. Special bulletin on maternal mortality in India 2010-12: sample registration system. New Delhi: Office of Registrar General, India-Vital Statistics Division, 2013.

3. National Health Mission. State wise information: Assam. Secondary State wise information: Assam. http://nrhm.gov.in/nrhm-in-state/ state-wise-information/assam.html

4. International Institute for Population Sciences (IIPS) and Macro International. National Family Health Survey (NFHS-3), 2005-06, India: Key Findings. Mumbai: IIPS, 2007.

5. Health Administrator. Assam. Health Administrator 2004; XVI(1). http://medind.nic.in/haa/t04/i1/haat04i1c.shtml (accessed 24 Mar 2013).

6. National Health Mission. Janani Suraksha Yojana. Secondary Janani Suraksha Yojana. http://nrhm.gov.in/nrhm-components/ rmnch-a/maternal-health/janani-suraksha-yojana/background.html

7. Planning and Development Department; Government of Assam. Chief Minister's Vision for Women \& Children. 2016. http:// planassam.info/Chief_Minister_Vision_for_Women_Children_2016. pdf (accessed 13 Oct 2015).

8. National Health Mission A. Maternal death reporting system (eMDR). Secondary Maternal death reporting system (eMDR). http:// nrhmassam.in/index.php

9. World Health Organisation. Beyond the numbers: reviewing maternal deaths and complications to make pregnancy safer. Geneva: World Health Organisation, 2004.

10. Office of Registrar General and Census Commissioner India. Annual Health Survey 2010-11: fact sheet. New Delhi: Ministry of Home Affairs, Government of India, 2012.

11. Office of Registrar General and Census Commissioner India. Annual Health Survey 2012-13: fact sheet. New Delhi: Ministry of Home Affairs, Government of India, 2014.

12. Souza JP, Cecatti JG, Haddad SM, et al. The WHO Maternal Near-Miss Approach and the Maternal Severity Index Model (MSI): tools for assessing the management of severe maternal morbidity. PLOS ONE 2012;7:e44129.

13. Halder A, Jose R, Vijayselvi R. Maternal mortality and derivations from the WHO near-miss tool: an institutional experience over a decade in Southern India. $J$ Turk Ger Gynecol Assoc 2014:15:222-7.

14. Sangeeta G, Leena W, Taru G, et al. Evaluation of severe maternal outcomes to assess quality of maternal health care at a tertiary center. J Obstet Gynaecol India 2015;65:23-7.

15. Knight M, Kurinczuk JJ, Tuffnell D, et al. The UK Obstetric Surveillance System for rare disorders of pregnancy. BJOG 2005;112:263-5.

16. Knight $M$, Lindquist $A$. The UK Obstetric Surveillance System: impact on patient safety. Best Pract Res Clin Obstet Gynaecol 2013;27:621-30.

17. Knight M, INOSS. The International Network of Obstetric Survey Systems (INOSS): benefits of multi-country studies of severe and uncommon maternal morbidities. Acta Obstet Gynecol Scand 2014;93:127-31.

18. Nair M, Choudhury MK, Choudhury SS, et al. The association between maternal anaemia and pregnancy outcomes: a cohort study in Assam, India. BMJ Global Health 2016;1:e000026.

19. Grewal A. Anaemia and pregnancy: anaesthetic implications. Indian $J$ Anaesth 2010;54:380-6.

20. Sarma HKD, Sarma HK, Kalita AK. A prospective study of maternal near-miss and maternal mortality cases in FAAMCH, 
Barpeta; with special reference to its aetiology and management: first 4 months report. J Obstet Gynaecol Barpeta 2015;1:100-6.

21. Montgomery AL, Ram U, Kumar R, et al. Maternal mortality in India: causes and healthcare service use based on a Nationally Representative Survey. PLOS ONE 2014;9:e83331.

22. Sri BS, Khanna R. Dead women talking: a civil society report on maternal deaths in India: Commonhealth and Jan Swasthya Abhiyan, 2014.

23. Rohilla M, Raveendran A, Dhaliwal L, et al. Severe anaemia in pregnancy: a tertiary hospital experience from northern India. $J$ Obstet Gynaecol Res 2010;30:694-6.

24. Bhalerao A, Kulkarni S, Ghike S, et al. Eclampsia: maternal and fetal outcome. JSAFOG 2013;5:19-21.
25. Sunita T, Desai RM, Hon N, et al. Eclampsia in a teaching hospital incidence, clinical profile and response to magnesium sulphate by Zuspan's regimen. IOSR J Dent Med Sci 2013;4:1-5.

26. Shirazee HH, Saha SK, Das I, et al. Postpartum haemorrhage: a cause of maternal morbidity. J Indian Med Assoc 2010;108:663-6.

27. Hussein J, Ramani KV, Kanguru L, et al. The effect of surveillance and appreciative inquiry on puerperal infections: a longitudinal cohort study in India. PLOS ONE 2014;9:e87378.

28. Jain V, Saha SC, Bagga R, et al. Unsafe abortion: a neglected tragedy. Review from a tertiary care hospital in India. J Obstet Gynaecol Res 2004;30:197-201.

29. Chhabra S, Bhagwat N, Chakravorty A. Reduction in the occurrence of uterine rupture in Central India. J Obstet Gynaecol 2002;22:39-42. 